\title{
Ethan Kleinberg: Teoría de la Historia como Fantología ${ }^{1}$
}

\section{Ethan Kleinberg: Theory of History as Hauntology}

\author{
André da Silva Ramos \\ Universidad Federal de Ouro Preto, Brazil \\ andramos7@gmail.com \\ Traducido por Liliana Patricia Mendoza Ortiz \\ Magister en Derechos Humanos y \\ Democratización de la Universidad Externado de Colombia \\ Universidad Federal de Ouro Preto, Brazil \\ Lilianamendozaortiz@ hotmail.com
}

\section{Resumen}

Ethan Kleinberg, es profesor de Historia y Letras de la Universidad de Wesleyan, director del Centro de Humanidades y editor ejecutivo de la revista History and Theory. Su primer libro, Generation Existential: Heidegger's Philosophy in France, 1927-1961, fue publicado por la Universidad de Cornell, y galardonado con el Premio Morris D. Forkosch 2006 al mejor libro de historia intelectual otorgado por la revista Journal of the History of Ideas. Recientemente, el profesor Kleinberg co-editó de la mano de Ranjan Ghosh el volumen Presence: Philosophy, History and Cultural Theory for the 21st Century, publicado también por la Universidad de Cornell. Por otro lado, su libro, Haunting History: For a Deconstructive Approach to the Past, fue lanzado en las Series meridianas de la Universidad de Stanford en el otoño de 2017.

Actualmente, se encuentra culminando su libro The Myth of Emmanuel Levinas, centrado en las lecturas Talmúdicas que el filósofo franco-judío presentó en París entre 1960 y 1990. En junio de 2016, tuve la oportunidad de llevar a cabo una entrevista con el profesor Kleinberg, cuando fui un estudiante visitante de investigación en el Centro de Humanidades de la Universidad Wesleyan. Además, aprovechamos la segunda Conferencia Internacional de Teoría de la Historia ( $2^{\text {a }}$ INTH), ocurrida en Ouro Preto, Brasil, del 23 de agosto al 26 de agosto, para ampliar la entrevista y para grabar una versión corta. El video se encuentra en el siguiente enlace: https://www.youtube.com/watch?v=PH9q_bJboHs

\section{Palabras clave}

Teoría de la Historia; Historia de la Historiografía; Fantología.

\footnotetext{
${ }^{1}$ Esta Entrevista fue publicada en inglés y en portugués por la revista brasilera História da Historiografia en el año 2017.
} 


\begin{abstract}
Ethan Kleinberg is Professor of History and Letters of Wesleyan University. He is the Director of the Center for Humanities and the Editor-in-Chief of History and Theory. His first book, Generation Existential: Heidegger's Philosophy in France, 1927-1961, published by Cornell University Press, was awarded the 2006 Morris D. Forkosch prize for the best book in intellectual history by the Journal of the History of Ideas. Recently, Professor Kleinberg co-edited with Ranjan Ghosh the volume Presence: Philosophy, History, and Cultural Theory for the 21st Century, published by Cornell University Press as well. His book, Haunting History: For a Deconstructive Approach to the Past, was released in the Meridian Series from Stanford University Press in fall 2017.

He is also finishing The Myth of Emmanuel Levinas, centered on the Talmudic Lectures that the French-Jewish philosopher presented in Paris between 1960 and 1990. I had the opportunity to conduct an interview with Professor Kleinberg in June 2016, when I was a Visiting Student Researcher at the Center for Humanities at Wesleyan University. We also took advantage of the Second International Network for Theory of History Conference (2nd INTH) in Ouro Preto, Brazil, from August 23 to August 26, 2016, to expand the interview and to record a short version. Here it is the link: https://www.youtube.com/watch?v=PH9q_bJboHs
\end{abstract}

\title{
Key Words
}

Theory of History; History of Historiography; Hauntology.

\section{1) Profesor Kleinberg, cuéntenos por favor, ¿cómo surgió su interés en el campo de la Teoría de la Historia y cómo afectó su carrera?}

Ethan Kleinberg: Cuando inicié mis estudios como estudiante de pregrado en la Universidad de Berkeley, mi enfoque fue en filosofía y yo creí que me convertiría en un filósofo. Pero cuanto más profundizaba en cuestiones filosóficas, más seguro estaba de que mi verdadero interés se encontraba en la relación entre el pensamiento intelectual y el contexto histórico. Esto me llevó a escribir mi más antigua tesis de la mano de Martin Jay, en el campo interdisciplinar de las humanidades. Después de terminar mi pregrado, sabía que debía asistir a la escuela de posgrado y nuevamente tuve un dilema para decidir qué disciplina perseguiría. Dado mi interés por la historia y porque los filósofos que me llamaron la atención (Heidegger, Benjamin, Foucault, Derrida y Kristeva) eran todos de tradición continental, la cual no se enseña tanto en los departamentos de filosofía de los Estados Unidos, decidí seguir la historia intelectual en el posgrado. Ingresé al programa de doctorado en UCLA y fue allí donde desarrollé mi interés y mi pasión por la teoría de la historia. Me preparaba como historiador intelectual europeo con un énfasis en la filosofía continental, pero esto ocurrió justo después de la famosa conferencia sobre el Holocausto en la UCLA que me llevó a conocer Probing the Limits of Representation, obra editada por 
Saul Friedländer. ${ }^{2}$ Yo formaba parte de una cohorte que estaba interesada tanto en la forma y la teoría de la historia como en la búsqueda de estudios de casos históricos; nos reuníamos en la biblioteca para discutir el último número de History and Theory. Trabajé cerca de profesores como Robert Wohl, Saul Friedländer, Peter Loewenberg y David Myers, y también tomé clases en el departamento de Literatura Comparada. Me beneficié de la presencia de Carlo Ginzburg, Perry Anderson, Eugen Weber y luego Lynn Hunt. Mi interés en el trabajo de Heidegger me llevó a Samuel Weber, que enseñaba en el departamento de Literatura Comparada y Jacques Derrida era en aquel momento profesor en UC Irvine. También conocí a Dominick LaCapra y Michael Roth, que no estaban en UCLA pero fueron muy generosos con su tiempo y apoyo. De este modo, caminé por una especie de cuerda floja entre la historia intelectual y la teoría de la historia, donde leí a figuras como Hegel, Benjamin, Rosenzweig, Heidegger y Kojève como modelos para la teoría de la historia y actores de la historia intelectual. Debo decir que los cursos que tomé con Sam Weber y Jacques Derrida fueron increíblemente influyentes para ayudarme a pensar en la teoría de la historia bajo una luz diferente y con diversas herramientas. A día de hoy, recomiendo a todos los estudiantes de posgrado que se muevan fuera de la disciplina elegida con la intención de salir de su campo y entender las múltiples lógicas de la erudición y la comprensión.

\section{2) ¿Podría contarnos un poco de su primer libro, sobre la recepción de Heidegger en Francia?}

E. K.: Generation Existential: The Reception of Heidegger's Philosophy in France, 1927-61 fue la base de mi tesis doctoral. ${ }^{3}$ Cuando comencé el proyecto me interesé inicialmente en las reacciones de la filosofía de Heidegger con la Alemania antes y después de la Segunda Guerra Mundial. Pero en la medida en que mi investigación progresaba, percibí que había en juego un tema mucho más histórico con respecto de la recepción y difusión de la obra de Heidegger en Francia. Específicamente, lo que me interesó fue la forma en que la filosofía de Heidegger fue reapropiada por pensadores predominantemente izquierdistas en Francia, a pesar de la afiliación bien conocida de Heidegger con el nacionalsocialismo. Argumenté que el proceso de recepción en Francia se regía por una doble lógica de heimisch y unheimlich en el que la filosofía de Heidegger fue reapropiada de formas que la hacían sentir en casa en Francia, pero también conservó un núcleo de lo desconocido haciéndola de alguna manera permanentemente extranjera. Utilizando el modelo de tres diferentes "lecturas" de la filosofía de Heidegger, pude apartarme del debate sobre si los pensadores franceses entendieron la filosofía de Heidegger de forma "correcta" o "incorrecta" (una estrategia argumentativa que caracteriza a los asuntos periódicos de Heidegger en Francia) y en su lugar me centré en las formas como las ideas se mueven a

\footnotetext{
${ }^{2}$ Saul Friedländer (org.), Probing the Limits of Representation: Nazism and the "Final Solution" (Cambridge, MA: Harvard University Press, 1992).

${ }^{3}$ Ethan Kleinberg, Generation Existential: Martin Heidegger's Philosophy in France, 1927-61 (Ithaca: Cornell University Press, 2005).
} 
través del tiempo, el lenguaje y el espacio. Estas tres lecturas son interpretaciones existencialistas de los años treinta y principios de los cuarenta, fuertemente influenciadas por la lectura heideggeriana de Kojève sobre Hegel y consolidada por la ontología fenomenológica de Sartre; un énfasis de la posguerra en Heidegger, que gira en torno a Jean Beaufret, que discute contra la lectura existencialista francesa para acentuar la preocupación de Heidegger por la historia de la metafísica y el olvido del Ser; y finalmente la crítica del pensamiento de Heidegger, adelantada por Blanchot y Levinas a la luz de la Shoah y la complicidad de Heidegger con el régimen nazi. Al final, como señaló Dominick LaCapra, el objetivo principal consistía en argumentar las diferentes lecturas y respuestas a la filosofía de Heidegger como respuestas más o menos complejas y codificadas con relación a cuestiones sociales, políticas y éticas más amplias.

\section{3) ¿Podría contarnos un poco sobre su relación personal y profesional con la revista History and Theory?}

E. K.: Como mencioné anteriormente, History and Theory fue muy importante a lo largo de mis estudios de posgrado $\mathrm{y}$, de alguna manera, fue el centro intelectual de mi trabajo. Pasé horas leyendo la revista y discutiendo con mis compañeros y profesores sobre los temas o debates de actualidad. De manera que ser editor ejecutivo ahora, es realmente un sueño hecho realidad. Cuando envié mi solicitud para la vacante en la Universidad Wesleyan, fue con la esperanza de lograr unirme finalmente al comité editorial y para mi buena fortuna se me permitió hacerlo en 2003. Desde entonces he trabajado activamente en la revista y, al igual que la escuela de posgrado, se ha convertido en el centro de mi vida intelectual. Pero más allá de esto, he desarrollado grandes relaciones con los otros editores: Gary Shaw, Vijay Pinch, Laura Stark, Matthew Spectre, así como con miembros de nuestro consejo editorial. También debo decir que Brian Fay, Phil Pomper y Dick Vann fueron figuras increíblemente influyentes para mí, especialmente Brian, quien sigue siendo un maravilloso mentor y amigo. Sería negligente por mi parte no mencionar a nuestra editora ejecutiva Julia Perkins, quien realmente hace funcionar la revista. Supongo que, en el fondo, History and Theory es tanto mi hogar intelectual como mi familia.

\section{4) ¿Hoy en día, cuáles son los principales desafíos de History and Theory?}

E. K.: Hay una serie de desafíos que, a día de hoy, enfrenta History and Theory. Creo que el primero es la precaria posición de la filosofía de la historia en la disciplina de la filosofía. Frank Ankersmit ha escrito sobre esto y al parecer cada vez menos y menos filósofos están siendo preparados para trabajar en este campo. Yo diría que tenemos que empezar a pensar de manera diferente sobre el valor de la filosofía de la historia y tal vez echar un vistazo a los filósofos que se dedican a cuestiones de temporalidad o campos como la ética de la virtud. Sin embargo, necesitamos encontrar maneras para dirigir a los filósofos hacia un interés sostenido en la teoría y el pasado. Un desafío distinto, pero importante, es el de la expansión del campo de la teoría de la historia más allá del canon occidental. Durante los últimos cinco años hemos trabajado duro para involucrarnos con académicos de China, India y América del Sur con el fin de dar continuidad a una conversación global más amplia sobre historia y teoría. Pero nos damos cuenta de que el deseo de fomentar una 
conversación más global, por loable que sea, también está lleno de dificultades. Como Vijay Pinch y yo hemos argumentado, "Occidente" es un referente geocultural difícil y resbaladizo; y, más aún, lo "no occidental". ¿Por qué la compulsión de ponerlos en citas de miedo? ¿Dónde termina Occidente? Sobre todo cuando una parte tan importante de los lectores globales y supuestamente "no occidentales" habitan culturas intelectuales que han surgido, históricamente, como resultado del diálogo intelectual y el intercambio político con Occidente, a pesar de que el diálogo y el intercambio hayan sido desiguales. Incluso algunas partes de la cultura intelectual que se resisten a Occidente no pueden dejar de ser moldeadas por su resistencia.

5) Como sabemos, el trabajo de Hayden White es famoso en todo el mundo porque fue capaz de demostrar la forma en que los tropos de la ficción funcionan en textos historiográficos. En su trabajo, percibo un cambio en el que utiliza textos de ficción para elaborar experiencias históricas latentes. ¿Podría describir cómo los historiadores pueden usar textos literarios para desafiar el canon de los estudios historiográficos de formas diferentes a las de Hayden White? ${ }^{4}$ En resumen, ¿cómo podemos pensar nuevas relaciones entre la Historia, la Filosofía y la Literatura para abrirnos a nuevas comprensiones y experiencias del tiempo histórico?

E. K.: El trabajo de Hayden White es increíblemente importante para pensar las formas en que la historia, especialmente las narrativas históricas, funcionan como literatura. Pienso que es un error inferir que esto signifique para White que el texto histórico sea pura fantasía, sino que hay que entender que el carácter del texto histórico es una forma particular o quizás un género de la literatura misma. Como puede notar, mi interés parte o tal vez se basa en el de White en la medida en la que me interesa lo que la literatura y específicamente la ficción literaria puede decirnos sobre el pasado y las formas en que pensamos en el pasado. En pocas palabras, las formas con las que el pasado asedia la historia. Para la mayoría de los historiadores, la ficción literaria se utiliza solamente como evidencia de algo o para algo. Esta no es importante en sí misma sino como evidencia para argumentar, por ejemplo, que el trabajo de Erich María Remarque en Francia o Ernst Jünger en Alemania puede informarnos sobre el clima cultural o intelectual de entreguerras en Francia o Alemania. Así cómo también las obras de Shakespeare nos hablan sobre los roles de género en la Inglaterra isabelina o Machado de Assis nos puede hablar sobre Brasil en el siglo XIX. Esto es, por supuesto, un argumento bastante utilitario sobre el valor de la literatura y la ficción literaria, pero diría que el surgimiento del nuevo historicismo muestra que esta valoración también se extiende más allá del gremio disciplinario de los historiadores hacia el ámbito de los eruditos literarios.

En mi opinión, la cuestión que más preocupa al historiador moderno es la posibilidad de una inversión en la que los asuntos de ficción, lo imaginario o lo irreal, tengan prioridad

\footnotetext{
${ }^{4}$ Nota del Traductor: Se adopta el género masculino teniendo en consideración la armonización de estilo, se resalta que tanto entrevistador como entrevistado comprenden la apertura de las prácticas historiográficas a todos los géneros.
} 
sobre las cuestiones de hecho, el "como realmente sucedió", la seguridad de que entendemos y comprendemos ese extraño artefacto llamado pasado. ; Si la historia se toma a sí misma como una "ciencia", seguramente no puede ser más afín a la literatura que a la neurociencia! Así, muchos historiadores solo encuentran valor en las obras literarias como hechos, evidencias, al servicio de la demostración.

Pero quiero abordar el tema desde otro ángulo y sugerir que la literatura y la ficción literaria pueden servir para desafiar aquel argumento utilitario al perturbar nuestras suposiciones subyacentes sobre lo que es "real", sobre hechos y ficciones, sobre nuestros propios supuestos utilitaristas y materialistas. Cuando utilizo las obras de literatura como un instrumento de un compromiso crítico con la historia, a menudo me preguntan ¿por qué elegiría las obras de ficción literaria para expresar mis ideas en lugar de las históricas? La respuesta es doble. Un aspecto depende de la obsesión del historiador con la fantasía de una ciencia histórica y la relación con la evidencia empírica. Con la ficción literaria, las apuestas probatorias son más bajas... no importa en absoluto si es "verdadero o falso" o si los eventos sucedieron. Por lo tanto, el historiador está dispuesto a participar en una discusión sobre la naturaleza fantasmal del pasado, demostrada a través de la obra de un autor como Charles Dickens de una manera muy distinta a la de tratar de utilizar una historia de fantasmas, el historiador se encontraría con la pregunta de "si los fantasmas existían o no", en lugar de lo que el fantasma puede decirnos acerca de nuestra relación con el pasado. Pero esta disminución de las apuestas, este "no importa", resulta mucho más importante en la medida que la literatura puede ser movilizada para criticar y cuestionar nuestras suposiciones históricas sobre el estatus privilegiado de los "hechos".

Esto quiere decir que la ficción literaria no tiene que ser "útil" en sentido utilitario, así como tampoco tiene que coincidir con lo que tomamos como "real". La literatura activa una ambigüedad perpetua que es también el lugar del significado porque se resiste a cualquier tipo de visión totalizante. Por lo tanto, como una cuestión de ficción, la literatura afecta a la tranquilidad que viene con la suposición de que lo que conocemos como una cuestión de hecho es una entidad completamente estable. Este es un pensamiento espeluznante para los historiadores, que temen que tal movimiento conduzca a un ballet fantasmal de relativismo moral y empírico, pero ir tan lejos sería simplemente invertir la jerarquía privilegiando la ficción enteramente sobre los hechos. Yo, en cambio, estoy interesado en las formas en que la literatura nos obliga a comprometernos con el papel que la imaginación desempeña en la creación de las coordenadas por medio de las cuales le damos un significado a la historia. La utilidad de la literatura aquí es su obstinada resistencia a la lógica de la utilidad. Lo que más importa es que no interesa ninguno de los sentidos argumentados por los filósofos morales, los neurocientíficos o los historiadores literarios. Por el contrario, lo que importa no son los resultados probatorios de los aspectos de hecho, sino las cuestiones aparentemente interminables engendradas por asuntos ficticios.

Pero esto me lleva al segundo aspecto de mi respuesta. Mientras que Hayden White estaba estudiando la forma de la literatura para iluminar su relación con las narrativas históricas, yo utilizo la ficción literaria como un sitio privilegiado que expone la forma en 
que el pasado asedia la historia. El pasado por definición se ha ido y por lo tanto no tiene propiedades ontológicas o se podría decir que tiene una ontología latente que se activa cuando hacemos historia. Pero esta activación del pasado es siempre parcial, dejando los restos ocultos o latentes. Este es un pasado que está ausente, pero que nos asedia y puede regresar alterando nuestras narrativas históricas convencionales y la comprensión de lo que es el pasado y la historia. A mi juicio, la ficción literaria es un sitio donde esta inquietud es particularmente fuerte. No obstante, los historiadores no están especialmente en sintonía con la lectura de literatura para la historia o tal vez no se les permite hacerlo. En cualquier caso, en mi lectura, la ficción literaria puede exponer nuestra relación con el pasado sin cerrarla o limitar futuras lecturas posibles. Esta es la historia como una comprensión rigurosa del pasado que, pese a todo, está abierta a la revisión continua, y que también nos pide repensar las coordenadas espaciotemporales por medio de las cuales tanto los filósofos como los historiadores sitúan los acontecimientos pasados como "historia".

6) Usted es bastante crítico con la tradición realista de los estudios históricos la cual se basa, en sus términos, en un enfoque ontológico-realista de la historia limitado por un techo analógico. Pero también es crítico con el enfoque de Hayden White con respecto a una discontinuidad aguda entre el lenguaje y la realidad. Al final, se compromete críticamente con la teoría de la presencia promulgada por Hans-Ulrich Gumbrecht, Frank Ankersmit y Eelco Runia, ya que afirma que la creencia de la teoría de la presencia en el contacto real con el pasado se basa en un enfoque conformista de la historia. ${ }^{5}$ Entonces, ¿cómo se sitúa en el escenario de la Teoría de la Historia? ¿Podría hablarnos sobre su reciente libro Haunting History: Deconstruction and the Writing of History ${ }^{6}$

E. K.: Hay varios aspectos en esta pregunta, así que intentaré tratarlos sistemáticamente. Empezaré con mi crítica de la comprensión convencional -que yo llamo ontológica realista- de la historia, porque creo que Hayden White, Hans-Ulrich Gumbrecht, Frank Ankersmit, Eelco Runia y yo somos críticos de esta posición incluso si podemos no estar de acuerdo en los detalles. Defino el realismo ontológico como un compromiso con la historia, como un esfuerzo relacionado con unos eventos asignados a un lugar específico en el espacio y el tiempo que son en principio observables y como tales son considerados como fijos e inmutables. Aquí el historiador acepta que existe una posibilidad de incertidumbre epistemológica en cuanto a nuestra comprensión de un acontecimiento pasado, pero esto se ve mitigado por la certeza ontológica de que el suceso ocurrió de cierta manera en un momento determinado. El problema de esta posición es su compromiso con los datos empíricos que le sirven como falso suelo para sostenerla. En última instancia, comprender el pasado "correctamente" es una cuestión de método histórico. Por lo tanto,

\footnotetext{
${ }^{5}$ Véase Rajan Ghosh y Ethan Kleinberg (orgs.), Presence: Philosophy, History, and Cultural Theory for the Twenty First Century (Ithaca: Cornell University Press, 2013).

${ }^{6}$ Ethan Kleinberg, Haunting History: for a deconstructive approach to the past (Stanford: Stanford University Press, 2017).
} 
una pregunta que debemos hacernos es ¿qué sostiene la certeza ontológica del acontecimiento pasado dada la posibilidad de incertidumbre epistemológica en la narración de ese evento? La mayoría de los historiadores convencionales, o bien evitan, o bien aplazan este asunto trabajando puramente en la suposición de que el método es suficiente para traer el pasado al presente. Pero el acontecimiento pasado no puede hacerse presente; así, cualquier reaparición es la visita prematura de un fantasma. Esto conduce a una pregunta más preocupante todavía, y es sobre la categoría de ontología en sí, y, específicamente la ontología o la fantología del pasado.

Donde no estoy de acuerdo con Hayden White, así como tampoco con Hans-Ulrich Gumbrecht, Frank Ankersmit y Eelco Runia, no es en la crítica de la historia disciplinaria convencional, sino en el hecho de si la historia como disciplina debe ser descartada para comprometerse productivamente con el pasado. En mi opinión, White, Gumbrecht, Ankersmit y Runia sostienen una especie de divorcio entre teóricos o filósofos de la historia y los historiadores en el que los primeros se ocupan de la investigación de nuestras relaciones individuales y / o colectivas con el pasado, mientras que los segundos languidecen en los archivos persiguiendo sueños realistas ontológicos. Para Hayden White, esto ha llevado a un enfoque constructivista basado en el papel del lenguaje y la narrativa donde el pasado está siempre y necesariamente ausente. Para Gumbrecht, Ankersmit y Runia esto ha llevado a la sospecha acerca del papel mediador del lenguaje o del discurso a favor de una relación no mediatizada con el pasado a través de la "presencia", el lugar en el que el pasado está absolutamente presente.

Como usted dice, soy simpatizante del paradigma de la "presencia", especialmente con respecto de las maneras en las que el pasado nos toca, incluso si no podemos tocarlo. Pero también soy profundamente crítico con el modelo de presencia de dos formas. En primer lugar, me preocupa la pasividad requerida en el modelo de presencia; a veces el movimiento de la "presencia" realmente excluye la posibilidad de cambio y justifica el statu quo a través de sus pretensiones de producir un acceso no mediado al pasado por medio del retorno a lo real. Esto sucede en la discusión de Runia, Abu Ghraib, en el énfasis de Gumbrecht en la Gelassenheit heideggeriana, en el "dejar que las cosas sean", y también en Ankersmit en la medida en que el pasado está literalmente presente, mediante de una "experiencia histórica sublime".

En segundo lugar, y creo que irónicamente, el énfasis en la presencia material del pasado en el presente es extrañamente similar al del enfoque realista ontológico en la medida en que ambos se basan en una lógica de presencia. Tanto el enfoque ontológico de aquellos filósofos de la historia cuyo enfoque es nuestro modo histórico de ser en el presente como el enfoque epistemológico de aquellos historiadores que se centran en la importancia del método para determinar la realidad del pasado ponen el énfasis, ambos, en lo que está presente y no en lo ausente. Runia, Gumbrecht y Ankersmit lo hacen argumentando la presencia del pasado en el presente. Mientras que los historiadores convencionales lo hacen al defender la presencia perdurable y recuperable del pasado como pasado. 
Acepto el énfasis de White en el lenguaje y algunos aspectos del modelo de presencia, pero mi enfoque fantológico de la historia sigue el juego de la presencia y la ausencia, de la presencia como ausencia y ausencia como presencia. En contraste con la búsqueda de los orígenes o del pasado material hecho presente, analizo a Derrida para hacer explícitas y comprometerme con las perturbaciones que el pasado devuelve y convoca. En el libro Mal de archivo, Derrida discutió nuestra relación con una tradición o legado, lo que él llamó un "rendimiento de repetición", donde la interpretación del archivo también implicaba interpretar e inscribirse en el archivo para tener un lugar legítimo en este. ${ }^{7}$ De este modo, Derrida ve la relación con el pasado como un proceso de autoinscripción en el que se lee e interpreta el archivo del pasado para crear un espacio en el presente. Pero, al mismo tiempo, las huellas del pasado llevan consigo una fuerza que rompe con su contexto y su momento. Esta apertura a la relación de presencia y ausencia a través del enfoque fantológico de la historia basado en una lógica de diferenciación explica la relación enmarañada entre presencia y ausencia sin privilegiar una sobre la otra. Todo esto para decir que la deconstrucción histórica, en mi trabajo, trata de operar con elementos del "constructivismo", pero sin renunciar a las pretensiones de compromiso con lo "real".

7) Usted es bastante crítico con la tradición de los estudios historiográficos concernientes a las creencias en las que se basan las prácticas de la historización. Critica tanto el enfoque realista de los historiadores con respecto a la posibilidad de ubicar cosas en el espacio y el tiempo, como los límites de las formas -artículos, monografías, disertaciones- que refuerzan estas perspectivas. ¿Podría construir un puente entre sus perspectivas teóricas con relación a la teoría de la historia y los desafíos contemporáneos que enfrentan las humanidades digitales? En el capítulo 4 de Haunting History, "The Analog Ceiling", usted trata directamente estos problemas. Por favor, cuéntenos un poco al respecto.

E. K.: Puedo basarme en la respuesta que le di anteriormente porque, en mi opinión, la actual dominación del realismo ontológico en la profesión histórica ya no es justificable con base en nuestra comprensión actual del pasado. Alun Munslow formuló esta cuestión hace varios años, cuando argumentó que los defensores de esta posición la mantenían mientras, simultáneamente, hacían concesiones a los filósofos o teóricos de la historia con respecto de las propiedades del pasado o con asuntos de escritura y representación. Dado lo anterior, podemos decir que en la práctica actual de hacer historia -la investigación, la escritura, la enseñanza- los historiadores convencionales reconocen la ignorancia, si no descartan directamente, las críticas, preocupaciones y construcciones articuladas en la teoría de la historia de los últimos cincuenta años. Esta ignorancia deliberada es lo que yo denomino el Techo Analógico, causado por las formas con que las prácticas actuales de las publicaciones académicas refuerzan el uso del realismo ontológico como el único modo viable de hacer historia. Este techo funciona porque permite argumentar que, aunque el pasado no se correlacione realmente con las reconstrucciones narrativas del realismo ontológico, es sin embargo la mejor analogía para hacer el pasado inteligible, entendible y

\footnotetext{
${ }^{7}$ Jacques Derrida, Archive Fever: A Freudian Impression (Chicago: University of Chicago Press, 1998).
} 
comprensible. Este argumento también sostiene que las restricciones de la publicación, los grados avanzados y la titularidad universitaria hacen que este sea el mejor y más viable formato para escribir sobre el pasado y para "hacer" historia. De esta forma, el realismo ontológico, la analogía más usada para representar el pasado, se ve reforzado por los límites analógicos de la edición tradicional, los cuales guían a los historiadores hacia la forma de la ficción realista. Nuestra capacidad de innovación está limitada debido a las formas en que las suposiciones del realismo ontológico y las limitaciones de las prácticas editoriales analógicas sirven para justificarse mutuamente como necesarias.

Incluso con las innovaciones en la teoría de la historia y con las herramientas o los formatos digitales disponibles, nos encontramos ante el peligro de simplemente reemplazar los antiguos formatos. Así, el artículo en línea parece ser exactamente el publicado en la revista. El e-book es indistinguible del códice. Estamos dando cabezazos contra el techo analógico en lugar de ver cómo estas innovaciones en la teoría y la forma pueden cambiar el modo de investigar, escribir y enseñar sobre el pasado. La forma en que hacemos la historia. Pero la disciplina de la historia se enfrenta a un cambio de paradigma y los historiadores cuyas mentalidades fueron formadas y restringidas por la imprenta deben hacer frente ahora a los cambios que los medios digitales provocan en cada aspecto de su disciplina. Una parte de este cambio es la posibilidad de reconceptualizar las obras históricas como multimodales, multitemporales y multimedia para resistir la presentación y las restricciones de una narrativa temporal monolítica. En estos modelos, el tiempo y el espacio están o pueden estar fuera de quicio, y es así como las nuevas formas se alinean con una reconstrucción narrativa fantológica centrada en la no simultaneidad, los caminos históricos divergentes y la inestabilidad del tiempo.

Aquí estamos hablando de las múltiples interacciones heterogéneas de una forma narrativa que no se despliega de manera estrictamente lineal, sino que se envuelve sobre sí misma en una topología polisémica no lineal. Una que desafía las suaves y continuas estrategias del realismo ontológico, pero que coincide mucho más estrechamente con lo que sabemos sobre el espacio y el tiempo, y cómo, en mi opinión, debemos pensar en la ontología latente del pasado. Tal narración acomoda una comprensión de lo que yo llamo pasado como algo que está, como presente $\mathbf{y}$ ausente al mismo tiempo, como algo y nada enredado de una manera aparentemente imposible, donde la posición iterativa del historiador está entretejida en el pasado y en el presente de tal manera que presiona el futuro.

8) En el capítulo 3 de Haunting History, "Chladenius, Droysen y Dilthey: Back to Where We've Never Been", usted explora cómo estos autores se enfrentaron a la crisis de la representación, demostrando cómo intentaron establecer una estabilidad histórica recurriendo a la teodicea o el método histórico. ¿De qué manera su lectura de estos autores muestra que el principal problema de los estudios historiográficos es la búsqueda de la estabilidad presente? ¿Cuál es el riesgo de la estabilidad?

E. K.: Una razón por la que me fijo en la tradición historicista alemana es porque estos pensadores a menudo se usan para justificar o validar enfoques teóricos $\mathrm{o}$ 
metodológicos actuales. En el libro cito un foro en la American Historical Review, donde el historiador intelectual americano David Hollinger se refiere a Dilthey para conceder la falibilidad del historiador, pero no la naturaleza definida o la recuperabilidad del pasado. En una línea similar, Felix Gilbert afirma que "Droysen está más cerca del enfoque histórico moderno que muchos historiadores de la generación que le siguió", 8 mientras que Blanke, Fleischer y Rüsen pueden reclamar que "para Droysen no es posible poner en peligro [el carácter empírico de la historia], pues todavía explica epistemológicamente la investigación histórica y encuentra los principios de su filosofía de la historia en los fundamentos epistemológicos de los estudios históricos". ${ }^{9}$ Y, más recientemente, el concepto de Chladenius del punto de vista o Sehepunkt, se ha desplegado al servicio de un argumento similar al de Hollinger, en el que se da la falibilidad del historiador, pero no la inestabilidad del acontecimiento pasado. Cada uno de estos argumentos sirve para determinar el pasado como un objeto estable y fijo, que se puede representar con precisión siempre y cuando el historiador se adhiera al enfoque metodológico adecuado.

El asunto clave aquí es que, como resultado de este enfoque, la inestabilidad del pasado es reemplazada por un sentido de la fijeza que se basa en la representación y en la reexperimentación del acontecimiento pasado. Lo que se propone es la creencia en la continuidad de los acontecimientos como si realmente hubieran sucedido como tales, no la realidad de esos acontecimientos. Pero la prioridad de la representación para asegurar esta creencia se borra a favor del poder de retención del propio acontecimiento originario. Una vez que se considera que la prueba del relato histórico es su adhesión a la realidad ontológica del acontecimiento pasado, el papel del historiador en ensamblar los fragmentos en un todo se degrada en un método epistemológico más que en una construcción ontológica. Es decir, el papel del historiador en la construcción de lo que se considera la realidad ontológica del acontecimiento pasado se borra. La repercusión consiste en que la naturaleza históricamente contingente de una representación histórica particular se considera válida para todos los tiempos $\mathrm{y}$, con esta, otra posible comprensión o representación histórica se cierra. Pero la ficción de un pasado estable es la ficción de un presente estable.

Lo que intento demostrar es la forma con la que las posiciones de Chladenius y Droysen se basan en una comprensión teológica del orden y de la estabilidad, en donde el pasado y el acceso al pasado se mantienen por el poder superior de Dios. La inestabilidad de esta posición, sin presencia de Dios, queda clara en la obra de Dilthey. No obstante, la mayoría de los historiadores y teóricos modernos sustituyen el método histórico por las posiciones religiosas de Chladenius y Droysen. Lo anterior nos lleva a una especie de tautología, dado que no es la presencia de Dios la que proporciona un terreno absoluto para acceder al pasado a través de una metodología adecuada, sino que es la realidad ontológica

\footnotetext{
${ }^{8}$ Felix Gilbert, “The New Edition of Johann Gustav Droysen's Historik”, Journal of the History of Ideas, vol. 44, 2 (1983): 327-336.

${ }^{9}$ Horst Walter Blanke, Dirk Fleischer y Jörn Rüsen,"Theory of History in Historical Lectures: The German Tradition of Historik, 1750-1900”, History and Theory, vol. 23, 3 (1984): 331-356.
} 
del pasado que ahora se convierte en el garante del esfuerzo histórico que define lo que la realidad ontológica del pasado debe ser. Los historiadores convencionales y algunos teóricos de la historia se han centrado en la cuestión epistemológica de un método riguroso universalmente válido para estabilizar esta investigación en el pasado. Al hacerlo, sin embargo, la tarea de crear una metodología universalmente válida se presenta como algo ya antes logrado. Esto a pesar de que ni Chladenius, ni Droysen ni Dilthey fueron capaces de lograr este ideal, ni tampoco es probable que tal ideal pudiese lograrse dada la confianza de Chladenius y Droysen en un andamio teológico y el énfasis de Dilthey en la historicidad del sujeto.

Pero tal "fracaso" solo puede considerarse si se pretende sostener la estabilidad rígida del pasado. En cambio, yo trato de observar estas figuras para pensar en la inestabilidad del pasado. Chladenius, Droysen y Dilthey pusieron todo el énfasis en la metodología del historiador en respuesta a la inestabilidad desencadenada por la realización y articulación del propio papel del historiador como un ser histórico para el que la historia es un problema. Utilizando el trabajo de Derrida, yo emparejo el punto de vista o perspectiva (el momento históricamente condicionado desde el cual iniciamos nuestra investigación de la historia) con la différance para cuestionar el punto de entrada en el círculo hermenéutico. De hecho, la misma noción de estabilidad se pone en cuestión por la compleja relación entre el historiador que opera dentro del contexto de su momento histórico y las fuentes (Quellen), los restos (Überreste) o los monumentos (Denkmäler) a través de los cuales el pasado asedia el presente y el historiador trata de comprender el contexto del pasado. Para los historiadores, el contexto nunca es absolutamente determinable porque siempre es determinado dentro de otro contexto. Si realmente queremos pensar en el pasado, en lugar de tratar simplemente de controlarlo, debemos aprender a centrarnos en su inestabilidad y las formas en las que este asedia la historia.

\section{9) ¿Podría hablar un poco sobre el libro en el que está trabajando ahora, The Myth of Emmanuel Levinas?}

E. K.: Tal como originalmente se pensó, este proyecto se centró en las lecturas talmúdicas de Emmanuel Levinas presentadas en París entre 1960 y 1990; los orígenes del giro de Levinas hacia el estudio del Talmud en los años posteriores a la Segunda Guerra Mundial; y la recepción de las lecturas talmúdicas de aquel. El propósito de la obra era descartar el "mito" de Levinas como un erudito talmúdico lituano experimentado y explicar las maneras y las razones por las que Levinas llegó a estudiar el Talmud después de la Shoah. Un componente clave de esta trayectoria fue también demostrar cómo Levinas ha influido en el pensamiento judío moderno al establecer una cadena de tradición posrabínica que permitió, a él y a sus sucesores, restablecer la tradición talmúdica tras la Shoah, no obstante desprovista de cualquier autoridad rabínica. Por lo tanto, el proyecto trató inicialmente sobre asuntos de legitimidad intelectual y sobre la creación de autoridad intelectual; $y$, en muchos sentidos continúa siendo así.

Sin embargo, a medida que el proyecto empezó tomar forma en capítulos, estaba cada vez más descontento con el resultado. En un ensayo de revisión de History and Theory y en 
un artículo sobre "Freud and Levinas" exploré el tema de la relación y los sesgos del proyecto de la historia con las pretensiones de la religión. Entonces me encontré repitiendo los mismos sesgos en mi trabajo sobre Levinas. En ese momento decidí volver a pensar en la arquitectura y la presentación del libro, en un intento de presentar simultáneamente una historia intelectual convincente de las lecturas talmúdicas de Levinas que proporcionara una lectura contextual de las fuentes y causas de su giro (esencialmente el proyecto original), pero que simultáneamente ofreciera una contra-interpretación que permitiera a las afirmaciones trascendentales de Levinas mantenerse "de buena fe". Esto quiere decir que mientras yo creo que una historia intelectual crítica del contexto que rodea el paso de Levinas al Talmud y la construcción de una "ética del otro" (una historia secular inmanente) está justificada y es necesaria, pienso que es igualmente importante plantear la presentación de Levinas de la naturaleza trascendente de la verdad divina en sus propios términos y como una interpretación igualmente plausible.

Uno podría considerar esto en el sentido más débil de la perspectiva múltiple, pero a lo que estoy intentando llegar es a la manera como el pasado es contradictorio e inestable... cosas distintas al mismo tiempo. Fue esta aporía, esta contradicción inherente al proyecto, la que me obligó a dejar de trabajar en ella y repensar cómo me acerco al proyecto de la historia, y esto me permitió escribir mi reciente libro sobre la deconstrucción y la historia. En el libro de Levinas utilizo la metodología deconstructiva o fantológica que explico en el libro sobre la deconstrucción.

10) ¿Podría presentar su tesis sobre la ambición de los historiadores para definir la historia como una disciplina en los mismos términos que los de las ciencias duras y cómo eso se relaciona con el neoliberalismo? En resumen, ¿podría hablar sobre su reciente artículo Just the Facts: The Fantasy of a Historical Science, publicado en la revista History of the present? ${ }^{10}$

E. K.: Un aspecto de la disciplina histórica que siempre me ha fascinado es la manera en que los historiadores regularmente ofrecen paradigmas para discernir la verdad del pasado que conocen, admiten que son inalcanzables y luego borran los aspectos del modelo que exponen las limitaciones e insuficiencias en las historias que escriben o cuentan. Creo que esto es lo que está en juego en el reciente giro hacia la "ciencia" entre los historiadores en Estados Unidos a través de la neurohistoria, la historia evolutiva, la historia biológica o la Gran Historia. Esta reciente fascinación por la ciencia es nueva y preocupante, dado que a mi juicio sirve para cerrar la discusión y el debate entre historiadores y científicos en lugar de promoverlos, pero también porque el impulso hacia ella es, en mi opinión, principalmente financiero. Un efecto adverso es que el pretendido acercamiento o conversación entre la biología y la historia es de hecho unilateral debido a que tiene lugar en los campos nomotéticos adscritos a la ciencia más que por medio de una investigación

\footnotetext{
${ }^{10}$ Ethan Kleinberg, "Just the facts: the fantasy of a historical science", History of the Present, vol. 6, 1 (2016): 87-103.
} 
sobre las formas en que cualquier ley natural puede problematizarse mediante la investigación histórica.

No obstante, hay una contradicción más perniciosa en acción. Los partidarios de la historia científica sostienen que, derribando la distinción entre las ciencias naturales y las humanas, revocan el privilegio del texto escrito y así eliminan los sesgos culturales e intelectuales que sostuvieron las narrativas de los "grandes hombres" del pasado. Pero lo que se presenta como un sentimiento democratizador en realidad es profundamente preocupante debido a la forma en la que se evacúa la política. La crítica de la razón como ejemplo de lo humano es la que ha animado a muchos teóricos e historiadores feministas, queer y críticos de la raza que han trabajado con esta noción desde al menos los años setenta. La falsa promesa de una humanidad universal científicamente determinada desconoce estos logros, despolitizando la historia y la historiografía.

Pero esto conduce a una cuestión aún más amplia. ¿Por qué debemos darle un lugar privilegiado a las ciencias duras, a sabiendas de que su discurso y su conjunto de disciplinas traen consigo grandes problemas de jerarquía, sesgo de género y presentismo? En el nivel más cínico/escéptico, mi respuesta es que la pregunta es principalmente económica, a pesar de las buenas intenciones de aquellos estudiosos que buscan ampliar los horizontes de la disciplina histórica. En los últimos veinte años, los historiadores se han dirigido cada vez más hacia la afiliación, primero, con las ciencias sociales y, luego, con las ciencias duras; tal movimiento sigue el auge de la iniciativa STEM (Ciencia, Tecnología, Ingeniería y Matemáticas por sus siglas en inglés) y la crisis percibida de las humanidades. No es sorprendente, ni siquiera una coincidencia, que, mientras los gobiernos federales, estatales y locales han invertido mayores cantidades en las "ciencias duras", las inscripciones en las humanidades, y en la historia en particular, hayan disminuido. La búsqueda del capital estimula ideas y paradigmas, y como resultado de ello ahora los historiadores corren hacia la ciencia en busca de esos fondos. A mi juicio, las opciones interpretativas de los neurohistoriadores o los defensores de la Gran Historia apoyados por Bill Gates deben ser vistas bajo esta luz, cualesquiera que sean los méritos de sus interpretaciones particulares. Tales opciones se alinean con las tendencias más generales tanto en su énfasis como en su financiación, a pesar de que tengan una posición supuestamente insurgente contra la corriente principal del trabajo histórico. Aquí, la lógica coincide con la del neoliberalismo en la medida en que vemos la disolución de las divisiones tradicionales del trabajo: el trabajo del historiador se consolida y sustituye por el del biólogo. En mi opinión, esto no es un acercamiento, una conversación o una interacción entre la historia y las ciencias, sino una rendición incondicional. Cediendo terreno a esta fantasía de la ciencia, los historiadores también ceden el espacio para la intervención crítica que es la fuerza y el corazón de nuestra disciplina.

11) Puedo encontrar algunas similitudes entre su lectura sobre los límites de la historiografía disciplinaria y su propuesta para explorar cómo el pasado asedia el presente, con la teoría de la modernización de Reinhart Koselleck y la noción de los estratos del tiempo. Sin embargo, a pesar del reconocimiento académico mundial del trabajo de Koselleck, es posible argüir las limitaciones de su historia conceptual para 
la transmisión del significado como un modelo para la investigación historiográfica. Aquí, el "paradigma de la presencia", que usted conoce bien, presenta otras posibilidades de investigación para teóricos de la historia e historiadores intelectuales. Me gustaría saber ¿cómo ve la importancia del trabajo de Koselleck para su enfoque y para los estudios historiográficos en general?

E. K.: Mi trabajo se sitúa en el marco articulado por Koselleck, en el que nuestra comprensión moderna de la "historia" se concibe como una fuerza en sí misma, generando aquellos tipos de cambios en los ordenamientos sociales que antes habían sido expresados como divinos, metafísicos, naturales o humanos. Pero yo sostengo que en este dominio hipostasiado de la historia como fuerza causal, las relaciones entre el pasado, el presente y el futuro comenzaron a superponerse o a descomponerse. Los acontecimientos pasados son traídos "de vuelta" al presente por obra de la historia, pero otros aspectos del pasado nos asedian, así como la historia misma a la que nos aferramos. Son los fantasmas de las cosas que inadecuadamente recordadas, mal enterradas o no enteramente borradas del registro que los historiadores tradicionales investigan rigurosamente y que tan a menudo apoyan las ideologías dominantes.

Así, es la atención de Koselleck en las temporalidades múltiples o disyuntas lo que parece tan bienvenido. Helge Jordheim presenta al Koselleck que ofrece una teoría radicalmente diferente de la superposición de estructuras y estratos temporales, sincronías y asincronías. ${ }^{11}$ El énfasis de Jordheim está en el tema de la periodización en Koselleck, pero mi interés está en las estructuras temporales solapadas y en la fricción entre estas estructuras, que expone lo que Koselleck llama Ungleichzeitigkeiten, asincronismo o no contemporaneidad. El fenómeno de Ungleichzeitigkeiten ocurre en momentos en que los elementos de un tiempo posterior se introducen como contemporáneos al evento descrito o representado. Lo fascinante es que, para Koselleck, este momento de disyunción es donde el tiempo está fuera de los puntos de unión entre la coincidencia y no coincidencia de la narración histórica con el acontecimiento pasado. En mi opinión, estos momentos fuera del tiempo son el sitio de la fantología, un deslizamiento entre pasado y presente. Este andamiaje de engranajes donde se superponen las múltiples temporalidades da cuenta de la forma en que los relatos históricos tradicionales tienden a "congelar" los acontecimientos representados, incluso cuando el acontecimiento es continuamente reelaborado y alterado por el relato mismo.

Koselleck presenta esto específicamente con relación a su metodología de la Begriffsgeschichte o "Historia de los conceptos". Al centrarse en el concepto (y especialmente en las formas en que los conceptos son reocupados, Umbesetzung), uno entra y sale del presente y desestabiliza los supuestos inherentes a la investigación histórica. De esta manera, el método de la Begriffsgeschichte se libera de lo que Koselleck llama "el

\footnotetext{
${ }^{11}$ Helge Jordheim, “Against Periodization: Koselleck's Theory of Multiple Temporalities”, History and Theory, vol. 51, 2 (2012): 151-171.
} 
movimiento circular ingenuo de la palabra a la cosa y viceversa". ${ }^{12}$ Pero pienso que la noción de Koselleck de reocupación puede llevarse más lejos si pensamos en ella como un medio para entender aquello a lo que Derrida se refiere como "habitar una tradición". Es más, se podría alinear la disyunción de la no simultaneidad con la aporía derridiana para negociar la disimetría constitutiva de un pasado que está-[o que es]. La paradoja temporal de cómo algo puede estar presente y ausente al mismo tiempo es abordada por el enfoque deconstructivo. Esta es la fantología, una teoría de las múltiples temporalidades y los múltiples pasados que convergen, o al menos pueden convergir, en el presente.

12) Considerando nuestra conversación sobre las ventajas de pensar la Teoría de la Historia como una fantología, me gustaría abordar brevemente algunos asuntos relacionados con los desafíos de la historiografía profesional brasileña contemporánea.

La historiografía profesional brasileña ha estado trabajando en la historización de nuestros pasados de tormento, como la historia de la esclavitud entre los siglos XVI y XIX y la historia de la dictadura en los años 60, 70 y 80. Sin embargo, a pesar de la historización historiográfica, estos pasados aún nos acechan en el presente. Los problemas del racismo y las demandas de una derecha no democrática en la sociedad brasileña son bien conocidos internacionalmente. ¿Cómo pueden los historiadores profesionales abordar estos temas inquietantes sin dar por hecho que es posible historizar estos pasados? ¿Podría explorar algunas estrategias que los historiadores profesionales pueden usar con el fin de lidiar con los espectros simultáneos, considerando si el énfasis unilateral en uno puede dar lugar a la aparición de los demás?

E. K.: Supongo que debería comenzar con la advertencia de que no soy historiador de Brasil y lo que sé de la historiografía brasileña ha venido de artículos recientes sobre el tema. Pero creo que su pregunta apunta a algunos de los asuntos clave que abordo en mi libro Haunting History.

Uno de los problemas con los enfoques tradicionales que se adscriben a la posición ontológica realista es que, incluso en los momentos en que se abren nuevos caminos posibles de interpretación, se cierran simultáneamente otros. Así, podría considerarse que los relatos historiográficos europeos tradicionales del Brasil restringen los tipos de historias o relatos que pueden considerarse "historia" o fuentes históricas apropiadas. Pero promover estas fuentes y construir nuevas "historias" que expliquen la historia de la esclavitud o de los pueblos indígenas no será suficiente si cada una de estas narrativas diversas busca un "terreno más firme" para establecer su propia identidad. Cuando la política de identidad entra en juego, aparece lo que yo llamaría una deconstrucción truncada y simplemente invierte la dinámica del poder en lugar de desestabilizarla. Aquí el rechazo de la deconstrucción es la represión de la comprensión de que no hay un fundamento estable.

${ }^{12}$ Reinhart Koselleck, Futures Past (New York: Columbia University Press, 2004), 86. 
Desde esta perspectiva, el principio organizador de la investigación histórica convencional y la relación con las ideologías o posiciones políticas dominantes o competidoras nunca se ponen realmente en tela de juicio, sino que simplemente se reposicionan para convertir al "colonizador" en el "colonizado". Lo que llamo el "techo analógico" refuerza estas limitaciones, restringiendo nuestras narraciones históricas al ámbito de la ficción realista y la narrativa lineal. Por el contrario, un enfoque fantológico reconoce la forma en que estos pasados competidores, conflictivos y polisémicos están siempre dentro de los demás y fomenta la exploración de nuevas formas para dar cuenta de ellos, incluso si busca contenerlos.

Lejos de implicar la muerte o la abdicación del autor, la deconstrucción de la historia requiere de un historiador fuerte y cuidadoso, cuyo estilo retórico guie al lector a través de los "poros" que la aporía simultáneamente introduce y reconoce. Es un "toma y daca" que hace que el lector sea consciente de las aperturas en juego y de la naturaleza polisémica del pasado. Todo esto sugiere que la historia convencional de Brasil, articulada por historiadores profesionales, está asediada por un pasado repleto de fantasmas que perturban esa misma historia: los fantasmas de los pueblos indígenas, de la conquista, de la esclavitud, de la dictadura y la agitación política. Una presentación más completa de la historia de Brasil sería aquella que diera espacio para que estos fantasmas aparecieran, aunque su apariencia fuera profundamente perturbadora debido a las formas en que compiten, se contradicen y se afectan mutuamente.

Esto no puede ser simplemente perspectivismo o hermenéutica dado que no es solo el punto de vista del historiador en el presente el que actúa sobre la historia, sino también el pasado mismo que presiona el presente independiente de nuestra voluntad, intención o deseo consciente.

13) Entre el 23 de agosto y el 26 de agosto de 2016, se realizó el segundo INTH en Brasil, en Ouro Preto. Tuvimos la oportunidad de conocer especialistas en los campos de la Teoría de la Historia, la Historia de la Historiografía, la Filosofía de la Historia y la Historia Intelectual de todo el mundo. Entre las muchas cosas interesantes que sucedieron en esa conferencia, destaco una primera reunión para crear una Red Latinoamericana dedicada a reunir especialistas comprometidos a pensar la historia. Usted tuvo la oportunidad de participar en la Mesa Redonda de Comentarios, cuyo propósito fue abordar los principales desafíos intelectuales que enfrentamos en esta reunión y los que enfrentaremos en el futuro. ¿Podría hablar un poco sobre sus impresiones con respecto del segundo INTH? ¿Qué piensa sobre la solidificación de INTH y otras redes internacionales con respecto al futuro de los estudios en los campos mencionados?

E. K.: Pienso que la reunión fue maravillosa, especialmente me impresionó la fuerza y la originalidad de los estudiantes de posgrado y los jóvenes académicos que trabajan en ese campo. En particular, fue una gran oportunidad para conocer a algunos estudiosos de América del Sur, Centroamérica y México y para cultivar nuevas relaciones. Estoy muy entusiasmado, además, con la creación de la Red Latinoamericana gracias al pensamiento 
creativo y vibrante que encontré en la conferencia. Todo esto me parece que es un buen augurio para el futuro de la teoría de la historia.

En cuanto al contenido del evento, me sorprendió una tensión expuesta en la parte más nietzscheana del tema de la conferencia: "Sobre las ventajas y desventajas de la historia para la vida". La gran ventaja del esfuerzo de INTH es el deseo de encontrar un terreno común para reunir a los estudiosos con un interés en la teoría y la filosofía de la historia de todo el mundo para comprometerse entre sí. Esta interacción sin duda es algo positivo, pero el deseo de encontrar un terreno común no está exento de problemas. Siempre hay un peligro cuando uno se embarca en el proyecto de comparación: que el proyecto se base en un grupo de control tomado como la "norma" en función del cual todos los demás grupos deban medirse. En nuestra conferencia, podría ser el concepto occidental de "historia", el concepto de Koselleck de "modernidad" o el modelo de Halbwachs de "memoria". El peligro aquí es que la reivindicación de un terreno común se basa realmente en una imposición teórica.

Sanjay Seth dejó claro este asunto cuando preguntó si el código histórico diseñado en Occidente era adecuado para la interpretación de las historias no occidentales. Guillermo Zermeño ofreció un argumento poderoso sobre cómo los historiadores y teóricos de la historia podrían construir una comprensión común de la historia en sintonía con nuestro esfuerzo, así como también sobre lo que diferencia cada lugar y las formas particulares de la historia que vienen de cada región. Por supuesto, esto también presenta peligros de entropía, distancia e inconmensurabilidad.

El conflicto entre el deseo de encontrar algo en común y, a la vez, abrazar la diferencia es irresoluble. A mi juicio, sin embargo, el futuro de la filosofía de la historia reside en esta intersección y esta tensión. Es más, diría que es la teoría la que proporciona el metalenguaje para abordar ambos extremos.

\section{Profile}

André da Silva Ramos es Doctor en Historia por la Universidad Federal de Ouro Preto (UFOP - Brazil), Magíster en Historia por la misma universidad. Profesor sustituto de Teoría e Historia de la Historiografía en la Universidad Federal de los Valles del Jequitinhonha y Mucuri (UFVJM - Brazil).

André da Silva Ramos got his Master's and PhD degree in History at Federal University of Ouro Preto (UFOP - Brazil). Nowadays, he is a temporary lecturer at the University of the Vales of Jequitinhonha and Mucuri (UFVJM), teaching Theory of History and History of Historiography. 
Fecha de recepción: 5 de mayo de 2018.

Fecha de aceptación: 26 de noviembre de 2018.

Publicación: 31 de diciembre de 2018.

Para citar este artículo: André da Silva Ramos, "Ethan Kleinberg: Teoría de la Historia como Fantología", Historiografías, 16 (julio-diciembre, 2018): pp. 108-126. 